\title{
Design Factors and Energy Cost of Restaurant Operations in a North-Central Region of the USA
}

Hyung-Chan Kim, Kansas State University, Kansas, USA

Joyce H. Hwang, University of Hawaii at Manoa, Hawaii, USA

This article was published as:

Kim, H. \& Hwang, J."Design Factors and Energy Cost of Restaurant Operations in a North-Central Region of the USA". The International Journal of

Environmental, Cultural, Economic \& Sustainability (2009) Volume 5, 257-265.

This manuscript is deposited in the K-State Research Exchange at http://krex.ksu.edu 


\title{
Design Factors and Energy Cost of Restaurant Operations in a North-Central Region of the USA
}

\author{
Hyung-Chan Kim, Kansas State University, Kansas, USA \\ Joyce H. Hwang, University of Hawaii at Manoa, Hawaii, USA
}

\begin{abstract}
According to the sustainable passive solar design theory, design factors including building orientation, size of window, and location of window are related to energy consumption. Based on thistheory, design factors such as a proportion of windows, orientation of window, and building orientationswere empirically tested in their relationship to energy cost of a restaurant. LEED ${ }^{\circledR}$ for Commercial Interiors indicated that this approach not only made a positive impact on public health and the environment, it also reduced operating costs and enhanced building and organizational marketability. Thepurpose of this study was to identify design factors that are related to energy consumption using actua operation's data of family restaurants in a north-central region. Restaurants located in the northcentral region in the U.S spent larger proportion of their operating expenses on energy. Family stylerestaurants were selected because they have similar kitchen equipment and seating allowance. Constructiondocument was acquired to gather size of operations and other design factors. Scatter plotsand correlation analysis were used to examine relationships between design factors and energy consumptionin each restaurant. Among the five family style restaurant operations in a north-central region that participated in this study, the size varied from 2810 square feet to 9138 square feet. Energy cost per cubic foot was then calculated using adjusted energy cost and total cubic footage of each restaurant. The building orientation did not show close relationship with energy consumption of restaurants. However, the proportion of south window indicated a negative relationship to the energy consumption. The findings of this study were based on 5 restaurants and thus there is a need for another study withbigger sample size to verify these findings. In addition, similar studies in different climateregions willbe beneficial in testing the passive solar design theory in restaurant operations.
\end{abstract}

Keywords: Sustainable Commercial Design, Passive Solar Design, Energy Saving Design

\section{Introduction}

Rapidly flucutating cost of electricity and natural gas add challenges in the restaurant industry characterized as labor-intensive and low profit margin compared to other industries. Most restaurant operators have encountered the significant increase in energy cost and made efforts to keep their energy cost to a minimum such as adopting energy saving equipment. According to National Restaurant Association (2001), common actions taken by table-service restaurants included installing low water dishwashers and toilet fixtures, modifying lighting fixtures, and serving customers water upon request.

Due to the climate of north central region in the US, restaurants in this region spend more proportion of their operating expenses on energy. The major part of the energy cost in this region resulted from heating which is about 22 percent of 
total operating costs compared to other regions' heating cost that ranged from 1 to 11 percent of total operating costs (Platts research and consulting, 2002).

Many tips for restaurants to save energy often involve upgrading the lighting system or the heating, ventilation, and air condition (HVAC) system to a more energy efficient model. Commercial kitchens and ventilation equipment companies have been adding energy saving features to their products as a response to the high energy cost environment. While these tips are helpful in reducing energy consumptions, an up-front investment to upgrade different parts of the operation is necessary which may place a burden on the operation's cash flow.

The passive solar design theory provides a new approach to save energy for restaurants by employing certain design features without necessarily buying expensive energy saving equipment. Instead of adopting new equipment, this approach utilizes what already exists such as sun energy in designing restaurants.

In contrast to an active solar system that requires a piece of solar equipment, a passive solar system utilizes natural thermal energy flow by radiation, conduction, and convection and does not necessarily involve mechanical equipment. There are no additional collectors or storage units. All of these functions are integral parts of a building structure and materials such as building orientation, window size and location, insulation, and thermal mass. Therefore, there is no additional cost for an additional heating resource. The system of passive heating collects and transports heat through the non-mechanical distribution system. As a result, passive solar systems cost little to nothing to operate and maintain. There is hardly any greenhouse gases emitted from a passive solar system in operation.

The purpose of this project was to examine design factors of existing restaurants in relation to their energy consumption to estimate the potential energy saving capability of those design factors. A total of five family-style restaurant operations in a city located in the North Central region provided their cases.

\section{Literature Review}

\section{Sustainable Design}

Sustainability represents a balance that accommodates human needs without diminishing the health and productivity of natural system (Mendler \& Odell, 2006). In these times of rapidly rising world population, increased demand on scarce resources, and continued pollution, sustainability is quickly becoming the dominant issue of our time.

The concept of sustainability has been introduced to combine concern for the well-being of the planet along with continued growth and human development. McDonough and Braungart (2002) explained that though there is much debate as to what the word actually suggests, one can put forth the definition offered by the 
World Commission on Environment and Development: "Meeting the needs of the present without compromising the ability of future generations to meet their own needs."

In its original context, this definition was stated solely from the human point of view. In order to embrace the idea of a global ecology with intrinsic value, the meaning must be expanded to allow all parts of nature to meet their own needs now and in the future.

Designing for sustainability requires awareness of the full short and long-term consequences of any transformation of the environment. Sustainable design is the conception and realization of environmentally sensitive and responsible expression as a part of the evolving matrix of nature.

Sustainable design directly or indirectly mitigates most of our environmental problems. The environmental impacts of buildings include erodied quality of life, open space consumed by sprawl, and communities challenged by traffic and congestion. Sustainable design can lead to a variety of economic benefitsfrom energy, water, and material savings as well as reduced maintenance and other operational costs (Fox and Murrell, 1989).

The principles of sustainable design can provide a broad awareness of the environmental impact, both locally and globally. Kim and Rigdon (1998) explained three principles: Economy of Resources is concerned with the reduction, reuse, and recycling of the natural resources that are input to a building, Life Cycle design provides a methodology for analyzing the building process and its impact on the environment, and Humane design focuses on the interactions between humans and the natural world.

\section{Energy Efficiency Design}

Bonda and Sosnowchik (2007) described that recent events continue to underscore the importance of energy efficiency. Rising prices, fossil emissions, dwindling oil supplies, and increase in resource-driven conflicts all point to the need to develop a transition to alternative, cleaner, more local, and equitably distributed sources of energy. Energy efficiency can help our environment and economy which can reduce cost of operation as well as low emission for developing renewable energy resources.

Commercial sustainable design can consider three major energy efficiency criteria which are energy efficiency lighting design, equipments and heating and cooling system. The entire lighting design must be accomplished efficiently in terms of capital and energy resources such as life cycle costs and operation energy costs. According to Platts research and consulting (2002), annual energy consumption of lighting in restaurants varied from 10 to $14 \%$ of operating costs in five climate zones in the US. Architectural form of building placement of windows and location of spaces are guided by the availability of daylight as primary source of illumination (Stein, Reynolds, Grondzik, and Kwok, 2006). A design with consideration of daylight can improve energy efficiency by 
minimizing the use of electricity for lighting as well as reducing associated heating and cooling loads.

Energy star labeled appliances are energy efficient and can save unwanted electricity cost. Bonda and Sosnowchik (2007) noticed that energy star products cost the same as non-labeled equipment, however estimated annual saving is 10$15 \%$. The energy efficiency in heating and cooling system is to achieve a high quality environment at a lower cost. Furthermore, alternative energy resources of heating and cooling system such as solar energy can be utilized for saving operation cost and achieve human comfort zone in interior spaces.

\section{Daylighting}

\section{Passive Solar Heating Design (PSHD)}

Solar energy, the energy from the Sun, drives the climate and weather and supports virtually all life on Earth. It is over 99.9 percent of the available flow of renewable energy (Scheer, 2002). Solar energy is a totally renewable and efficient energy resource for sustainable design strategy.

PSHD is about maximizing the solar energy transformation to heating resource without any equipment. There are several methods for PSHD which include direct gain, thermal storage wall, sunspace, and water wall system. The direct gain system let the sun light enter through south windows or skylight and store the heat from the sunlight to serve entire top floor of a building. Large area's thermal mass surface should have darker color and be free of rugs, wall hangings, and etc. Light-colored surfaces near glass reduce glare. The heating characteristics of direct gain are quick warm up in the morning; fast response to sun; and tendency to overheat at midday. Warmth spread throughout space along with thermal mass as well as utilizing daylight resource for electricity cost saving.

According to Department of Energy Report (2004), some of the variables involved in passive solar heating system include:

1. Climate (sun, wind, sir temperature, and humidity)

2. Building orientation (glazing and room layout)

3. Building use type (occupancy schedules and use profiles)

4. Lighting and daylighting (electric and natural light sources)

5. Building envelope (geometry, insulation, fenestration, air leakage, ventilation, shading, thermal mass, and color)

6. Internal heat gains (from lighting, equipment, machinery, and people)

7. HVAC (Plant, system, and controls)

8. Energy costs (fuel source, demand charges, and conversion efficiency)

\section{LEED (Leadership in Energy and Environmental Design)}

The Leadership in Energy and Environmental Design (LEED) Green Building Rating System ${ }^{\mathrm{TM}}$ can be another resource of guidelines for designing more energy 
efficient restaurant operations. As reported by U.S Green Building Council (2006), LEED supports tools and performance criteria that can result in more sustainable green buildings and practices. Five key areas of human and environmental health identified by LEED include sustainable site development, water savings, energy efficiency, materials selection and indoor environmental quality. Tools provided by LEED can lead to an immediate and measurable impact on buildings' performance. LEED promotes a whole-building approach to sustainability and is the nationally accepted benchmark for the design, construction and operation of high performance green buildings.

\section{Method and Procedure}

\section{Sample}

To minimize influence of variables other than design factors on energy cost, family-style restaurants in a stand alone building in a North central region in the US were targeted. Family-style restaurants have similar menu profiles that require similar kitchen equipment, thus difference in energy cost caused by different equipment can be minimal. Dining areas of the restaurants share similar seating allowance. As heating efficiency can be influenced by seating density in the dining area, similar seating allowance can control influence of seating density on energy consumption. In addition, restaurants located in a stand-alone building were chosen to control differences in energy consumption between stand-alone units and units that are attached to a large building complex. The restaurants were served by the same energy service provider and thus the unit energy cost was the same.

\section{Data collection}

Upon approval from a restaurant, a construction document was acquired. From the construction document, design factors such as floor size, cubic footage, window size, and orientations of windows and entire buildings were recorded.

Energy cost was collected and adjusted to reflect same amount of operating hours, because each restaurant had different operating hours and holidays.

\section{Findings}

Based on restaurants' data, size and orientation of windows indicated a possible relationship to total energy consumption. Due to policies in many corporate companies, most chain restaurants were reluctant to share their energy cost information and the process of getting an approval from corporate office was difficult. As a result, a total of five family-style restaurants were recruited that included one restaurant which is not a stand-alone unit. The restaurant, however, is located at the end of a building; therefore, only one side of the restaurant is attached to the building.

\section{Overall restaurants' profile}


Size of the restaurants varied from 2,810 to 9,138 square feet. The wall structure of all five restaurants was composed of 4- to 6-inch wood stud filled with insulation material of R-16 or 19 covered with $1 / 2$ inch plywood and Tyvek building paper. These walls were finished with either brick, aluminum siding, or waterproof stucco. According to the Department of Energy, R-15 or higher wall cavity insulation rating is recommended in the North Dakota area.

Participating restaurants had similar window type, glazing, frame materials and insulation ratings. Window frames were made by all aluminum frames. The glazing type of all five restaurants was duble grazing which were two panes of glass sealed together with air or argon gas trapped between them to act as an insulator and it was low-emissivity glazing which was a film applied to one of glass surfaces between the panes. This film allows light in but also prenvents heating and cooling loss during different seasons.

Because each restaurant had different open hours, the annual energy cost was adjusted to reflect the same amount of open hours. Energy cost per cubic foot was then calculated, using adjusted energy cost and total cubic footage of each restaurant. Table 1 summarized the restaurants' size and energy cost profile.

Table 1. Restaurants' size and energy cost profile

\begin{tabular}{|c|c|c|c|c|c|c|c|c|}
\hline $\begin{array}{l}\text { Rest- } \\
\text { urant }\end{array}$ & $\begin{array}{l}\text { Total floor } \\
\text { size (sq ft) }\end{array}$ & $\begin{array}{c}\text { Total } \\
\text { cubic feet }\end{array}$ & $\begin{array}{c}\text { Main } \\
\text { entrance } \\
\text { location }\end{array}$ & $\begin{array}{l}\text { Kitchen } \\
\text { location }\end{array}$ & $\begin{array}{c}\text { Hall } \\
\text { location }\end{array}$ & $\begin{array}{c}\text { Annual } \\
\text { energy cost }\end{array}$ & $\begin{array}{c}\text { Annual } \\
\text { energy cost } \\
\text { adjusted }\end{array}$ & $\begin{array}{l}\text { E per } \\
\text { cu } \mathrm{ft}^{1)}\end{array}$ \\
\hline 1 & & & & & & & $\$ 97,885.04$ & $\$ 0.9$ \\
\hline 2 & & 126,5 & & & & & $\$ 74$, & $\$ 0.59$ \\
\hline 3 & 2.49 & $51,835.78$ & & & 1 & 5.13 & $\$ 71$ & $\$ 1.38$ \\
\hline 4 & & 703, & & & & 1.50 & $\$ 12$ & $\$ \quad 0.18$ \\
\hline 5 & $2,810.13$ & $33,721.56$ & West & South & North & $\$ 19,711.43$ & $\$ 27,376.99$ & $\$ \quad 0.81$ \\
\hline
\end{tabular}

* Energy cost per cubic foot was calculated as annual energy cost adjusted divided by total cubic footage.

Proportion of the window to total wall space of the building varied among restaurants from 9 to 34 percent. In addition, proportion of window space in each side of the buildings varied. Table 2 summarized each restaurant's window profile.

Table 2. Restaurants' window profile

\begin{tabular}{|c|r|r|r|r|r|r|r|}
\hline Restaurant & $\begin{array}{c}\text { Total } \\
\text { wall (sq } \\
\text { ft) }\end{array}$ & $\begin{array}{c}\text { Total } \\
\text { window } \\
\text { (sq ft) }\end{array}$ & $\begin{array}{c}\text { Win\% } \\
\text { to Wall }\end{array}$ & $\begin{array}{c}\text { North } \\
\text { win \%* }\end{array}$ & $\begin{array}{c}\text { East } \\
\text { win \%* }\end{array}$ & $\begin{array}{c}\text { South } \\
\text { win \%* }\end{array}$ & $\begin{array}{c}\text { West } \\
\text { win \%* }\end{array}$ \\
\hline 1 & 3013.25 & 1037.52 & $34 \%$ & $0 \%$ & $33 \%$ & $29 \%$ & $38 \%$ \\
\hline 2 & 6039.30 & 1114.12 & $18 \%$ & $2 \%$ & $41 \%$ & $46 \%$ & $12 \%$ \\
\hline 3 & 3610.50 & 989.80 & $27 \%$ & $27 \%$ & $18 \%$ & $16 \%$ & $40 \%$ \\
\hline 4 & 3102.30 & 290.70 & $9 \%$ & $0 \%$ & $46 \%$ & $41 \%$ & $13 \%$ \\
\hline
\end{tabular}


\begin{tabular}{|l|l|l|l|l|l|l|l|}
5 & 2330.40 & 307.50 & $13 \%$ & $53 \%$ & $0 \%$ & $7 \%$ & $40 \%$ \\
\hline
\end{tabular}

* The window percentage is calculated as window square footage facing one direction $(\mathrm{N}, \mathrm{E}, \mathrm{S}$, or $\mathrm{W})$ divided by total window square footage.

\section{Design factors that matter}

The building orientation did not show close relationship with energy consumption of restaurants. On the other hand, more window space can mean higher energy cost per cubic foot, according to the possible positive relationship illustrated in Figure 1. When looking at proportion of window facing different directions, having more windows facing south seemed to help reduce the energy consumption (Figure 2). 
Figure 1. Energy cost per cubic foot and window space ratio compared to total wall space

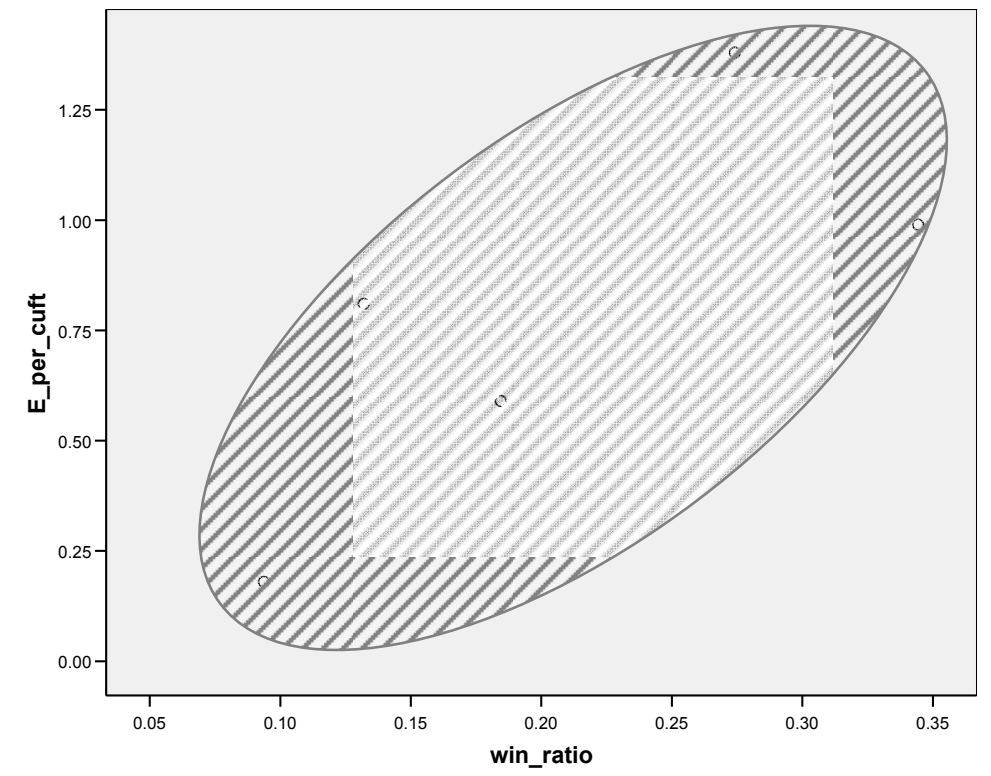

Figure 2. Energy cost per cubic foot and south window space ratio compared to total window space

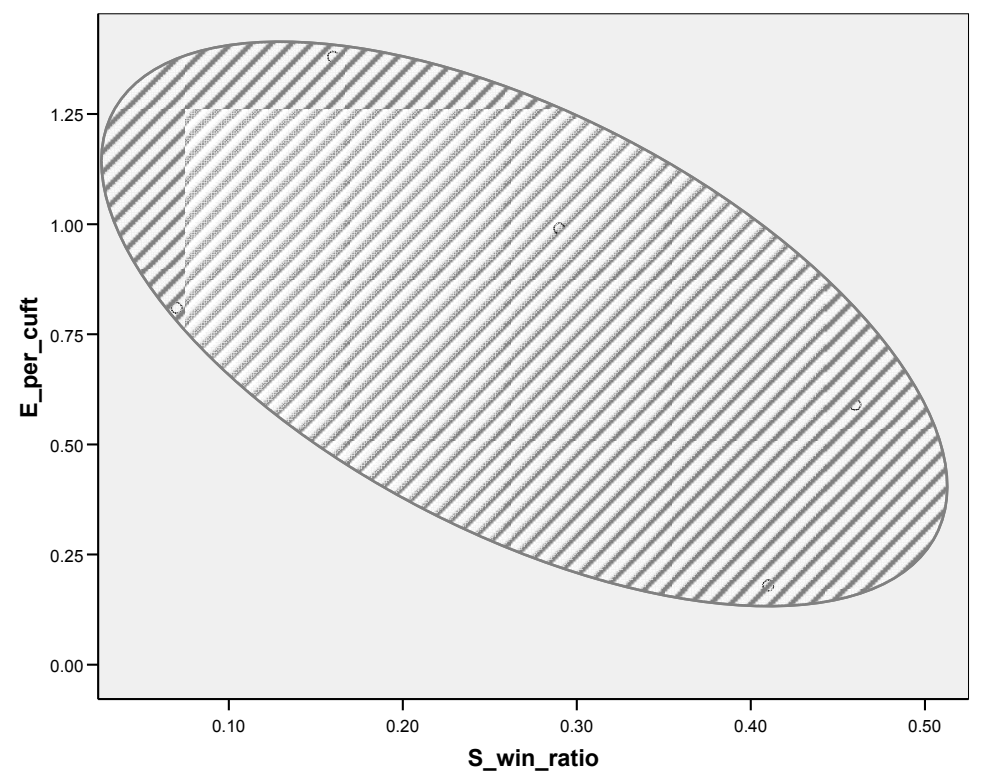

\section{Conclusion}

The passive solar design theory can present a new approach to save energy consumption for restaurant operations in a time when energy cost is skyrocketing. Based on this theory, design factors such as a proportion of windows, orientation 
of window, and building orientations were empirically tested in their relationship to energy cost of a restaurant.

Based on a small number of participating restaurant data, the results show a possible positive relationship between proportion of window and total energy cost while a negative relationship seems to exist between proportion of south oriented windows and total energy cost.

Windows are an essential part of a building for a number of reasons. Outside views become a part of the inside's décor through windows. Windows also let sunlight inside a building. In addition, the findings suggest that it may be possible to reduce overall energy consumption of a restaurant, based on location and size of windows. A careful plan of windows in the design stage may influence energy efficiency of a restaurant building.

A further study with a larger sample to minimize influence of other factors should be conducted to verify the findings of this study. With the larger sample, factors such as insulation type, wall thickness, and types of lights can be better controlled. In addition, future studies can examine the relationships of design factors and energy consumption by different climate regions. 


\section{References}

Bradshaw, Vaughn. The Building Environment. New Jersey: John Wiley \& Sons, Inc., 2006.

Fox, Avril, and Robin Murrell. Green design: a guide to the environmental impact of building materials. Architecture Design and Technology Press. London, 1989.

Kim, Jong-Jin, and Brenda Rigdon. Sustainable Architecture Module:

Introduction to Sustainable Design. National Pollution Prevention Center for Higher Education. Ann Arbor, 1998.

Lechner, Norbert. Heating, Cooling, Lighting. New York: John Wiley \& Sons, Inc., 2000.

LEED for Commercial Interiors. 2006.

http://www.usgbc.org/ShowFile.aspx?DocumentID=684 (accessed October 20, 2006).

McDonough, William, and Michael Braungart. Cradle to cradle : remaking the way we make things. New York: North Point Press, 2002.

Mendler, sandra, and William Odell. The HOK Guidebook to Sustainable Design. Hoboken, N.J. : Wiley, 2006. National Restaurant Association. 2 August 2001. http://www.restaurant.org/pressroom/pressrelease.cfm?ID=280 (accessed September 13, 2007).

Platts Research and Consulting. 2002. http://www.reliant.com/files/433802_CEA_restaurants.pdf (accessed October 5, 2006).

Scheer, Hermann. The Solar Economy: Renewable Energy for a Sustainable Global Future . London: Earthscan, 2002.

Sosnowchik, Katie, and Penny Bonda. Sustainable Commercial Interiors. New Jersey: John Wiley \& Sons, Inc., 2007.

Stein, Benjamin, John S. Reynolds, Walter T. Grondzik, and Alison G. Kwok. Mechanical and Electrical Equipment for Building. New Jersey: John Wiley \& Sons, 2006.

U.S. Department of Energy. 2007. http://apps1.eere.energy.gov/consumer/your home/designing remodeling/ index.cfm/mytopic=10250 (accessed Dec 12, 2007).

U.S. Gren Building Council. 2006. http://www.usgbc.org/DisplayPage.aspx?CMSPageID=222 (accessed May 15, 2007).

Winchip, Susan. Designing a Quality Lighting Environment. New York: Fairchild, 2005.

Winchip, Susan . Sustainable Design for Interior Environments. New York: Fairchild Publications, Inc., 2007. 